\title{
Are patients undergoing treatment of hyperlipidaemia with statins the best candidates for early cardiac rehabilitation?
}

\author{
Rafał Celiński', Anna Grzywa-Celińska², Wojciech Myśliński², Andrzej Dybała², Jerzy Mosiewicz²
}

\author{
1Department of Cardiology, Cardinal Wyszynski's Hospital, Lublin Poland \\ ${ }^{2}$ Chair and Department of Internal Diseases, Medical University of Lublin, Poland \\ Submitted: 7 February 2010 \\ Accepted: 24 July 2010
}

Arch Med Sci 2011; 7, 5: 756-759

DOI: 10.5114/aoms.2011.25548

Copyright @ 2011 Termedia \& Termedia

\author{
Correspondence author: \\ Rafał Celiński PhD \\ Department of Cardiology \\ Cardinal Wyszynski's Hospital \\ 100 Kraśnicka \\ 20-718 Lublin, Poland \\ e-mail: rcelinski@op.pl
}

\begin{abstract}
The role of statins in the primary and secondary prevention of cardiovascular events is well known. An important adverse event associated with statin treatment is myopathy; intensive physical effort in patients treated with statins increases the risk of muscle injury/myopathy. In this article we discuss the benefits and risks associated with statin treatment in patients undergoing cardiac rehabilitation after acute coronary syndromes and/or coronary revascularization procedures. In our opinion, the benefits of the secondary prevention of coronary heart disease achieved with statins seem to outweigh the hazards associated with statin therapy. The careful selection of patients for both treatment with statins and the gradual intensification of physical training in the course of cardiac rehabilitation appears to constitute an important element of the therapeutic approach.
\end{abstract}

Key words: statins, myopathy, early cardiac rehabilitation.

\section{Introduction}

Physical activity is still an underestimated primary and secondary prevention factor for the reduction of the risk of acute coronary events. The aim of cardiac rehabilitation is the shortening of treatment time after acute coronary syndromes (ACS), the independent functioning and occupational activity for as many patients as possible, as well as the prevention of disability and the consequent financial burden on the state [1]. Data from the "Report of the condition of cardiac rehabilitation in Poland" in 2004 [2] confirm the high effectiveness of cardiac rehabilitation in patients with coronary heart disease (CHD). Cardiac rehabilitation may lower cardiac mortality by $20-25 \%$ and the percentage of deaths during the first year after myocardial infarction (MI) by $35 \%$.

Most patients after ACS are automatically qualified for statin therapy; some of them start the treatment at almost the same time as the beginning of their cardiac rehabilitation. Some studies have reported an increased prevalence of myopathy in patients under intensive hyperlipidaemia treatment [3]. Thus, the risk of statin-induced myopathy should be taken into account in all patients treated with statins with simultaneous intensive cardiac rehabilitation, especially in older patients. 
The aim of our review article is to emphasize that apart from the appropriate selection of drugs and doses, there should be a focus on good cooperation between the medical team and the patient. This cooperation would guarantee immediate reporting of undesirable symptoms, so as to quickly withdraw the patient from the therapy and avoid life-threatening complications.

\section{Statins and exercise - good or poor combination?}

Cardiac rehabilitation is a good method of treatment for patients with stable CHD, with a history of ACS [4], percutaneous coronary interventions $(\mathrm{PCI})$ and coronary artery bypass grafting (CABG). A well-organized programme of physical training in patients with coronary dysfunctions has many physiological, biochemical and haemodynamic benefits.

In Poland a three-stage model of cardiac rehabilitation is currently used. The first stage is inhospital rehabilitation. The second is early cardiac rehabilitation practised at home, in ambulatory or stationary conditions. The third stage is late rehabilitation, undertaken to maintain the effects of previous treatments and rehabilitation, as well as to prevent further coronary episodes.

Once the patient leaves the hospital, he is qualified to begin early cardiac rehabilitation. Its foundation is rehabilitation based on exercising and physical training. The essential effect of physical training is a decrease in the heart rate, both during rest and at the time of exercise. The effect of appropriately chosen training is a reduction of the demand of the heart for oxygen during major exercise, which decreases the risk of acute heart ischaemia. It causes regeneration of the vascular endothelium and, as a result, an increase of nitrogen oxide production, which widens the vascular bed. It enables a significant broadening of the scope of life activities among patients. Physical efficiency can increase in patients with CHD up to 20-30\% by physical rehabilitation.

The most frequently recommended form of physical rehabilitation is interval training on a bicycle ergometer, because it enables precise control of load, pulse rate and blood pressure and, if needed, constant observation of heart functioning on the monitor with a graphic record on an ECG monitor [5].

Physicians often recommend this kind of treatment in support of pharmacotherapy, because the results of early cardiac rehabilitation are promising: they improve not only the patients' physical efficiency but also their quality of life.

Until now, we have only described the positive effects of increased physical activity in patients after ACS. However, experience from our clinical practice and a review of the literature on this topic, while obviously not negating the undeniable evidence of the beneficial effects of exercise, strongly suggest that in some groups of patients special precautions should be taken, careful consideration made, and accuracy should be maintained in informing patients about the potential side effects of combining two factors: pharmacotherapy with statins and physical exercise.

The role of statins in both the prevention of CHD and after acute coronary episodes has been well demonstrated in many studies [6]. One of the most important aims of modern medicine is to lower cholesterol levels; some researchers call it a medical obsession [7]. Since statin use has become common, and especially since their use has been introduced in recommendations for treatment of patients after an ACS, reports on substantial side effects of hyperlipidaemia treatment have appeared, apart from descriptions of the excellent effectiveness of these drugs. Due to the benefits of statin therapy proved in studies, the risk of this therapy tends to be underestimated. Statins belong to a group of drugs well tolerated among patients. They are administered only once a day and they can be used in monotherapy or as part of combination treatment [8]. However, they can provoke various side effects, ranging from dyspeptic symptoms, through moderately intense pain ailments, to the most severe ones such as liver damage and acute cell injury in the muscular system - rhabdomyolysis [9].

The safety of aggressive hyperlipidaemia therapy has been the subject of many analyses. The results of the PRIMO (Prediction of Muscular Risk in Observational Conditions) study, which included 7924 patients with drug therapy of hyperlipidaemia in various doses, was published in 2005. Muscular symptoms were observed in $10.49 \%$ of patients. The highest risk was noted in patients taking simvastatin (18.2\%) and the lowest (5.1\%) in patients taking fluvastatin [10]. In earlier studies, the average frequency of rhabdomyolysis occurrence during monotherapy with atorvastatin, pravastatin or simvastatin was 0.44 , with fibrates 2.82 , and with cerivastatin $\left(1^{\text {st }}\right.$ generation statin which was withdrawn in 2001) 5.34 cases per 100000 patients per year. This frequency rose to 5.98 if atorvastatin, pravastatin or simvastatin was used together with fibrates [11]. Based on studies carried out on healthy people, the frequency of moderately intense pain ailments is estimated at 190, myopathy with a significant increase in creatine kinase (CK) level at 5 and rhabdomyolysis at 1.6 cases per 100000 patients per year [12].

The frequency of rhabdomyolysis estimated in various studies is definitely affected by differences in the definition of this disease. To diagnose 
rhabdomyolysis, the most commonly used criterion is a sudden increase of serum CK levels exceeding at least fivefold the upper normal limit after excluding myocardial infarction (CK-MB fraction $<5 \%)[13]$.

The risk of myotoxicity during hyperlipidaemia treatment with statins increases during simultaneous therapy with drugs impeding statin metabolism, which include itraconazole, erythromycin and nefazodone [14], or others which can cause muscle inflammation, such as cyclosporine, macrolide antibiotics, niacin, azole antimycotic drugs, protease inhibitors or calcium channel blockers [15]. The risk of statin-induced myopathy is also increased in electrolyte imbalance, severe infections, injuries and hypoxia [14], as well as in hepatic disorders and renal failure $[15,16]$. In the last two pathologies, the risk is related to the dose of statins [17]. Hypothyroidism may also predispose to rhabdomyolysis [18]. The risk of myopathy also increases significantly in patients with congenital muscular defects, in patients with alcohol-related diseases, in people from the Mongoloid race and in people consuming large amounts of grapefruit juice [19].

A few articles provide information concerning life-threatening side effects of simvastatin therapy [20-22]. A recent topic of discussion is the role of genetic factors in the occurrence of statin-induced myopathy, which can influence the pharmacokinetics of these drugs and play a part in causing metabolic muscular diseases. Gene mutations responsible for metabolic muscular diseases were found in $10 \%$ of patients with statin-induced myopathy but only in 3\% of patients who tolerated statins well [23].

Finally, a crucial factor predisposing to rhabdomyolysis in patients undergoing statin therapy is loading with physical effort $[16,24]$.

The study of Thompson et al. published in 1997 [25] analysed the hypothesis that physical effort in the course of statin treatment causes a higher increase of muscle damage factor activity (CK) than physical training in patients who were not taking these drugs. Fifty-nine men with LDL $>130 \mathrm{mg} / \mathrm{dl}$ in spite of dietary therapy were examined. These patients were given $40 \mathrm{mg}$ of lovastatin or a placebo over a 5 -week period. Moreover, after 4 weeks of therapy, they underwent a 45-min treadmill test in order to assess maximal expected heart rate. In the following week, the patients trained using a different set of exercises. The activity of CK was examined before and after physical effort. It was demonstrated that the activity of $\mathrm{CK}$ in the group taking lovastatin was higher by $62 \%$ to $77 \%$ than in the case of physical training. Therefore, it was hypothesized that statins intensify muscle damage connected to physical training.
In the study published by Coen et al. [26], physically inactive patients with hypercholesterolaemia were divided into 2 groups. Patients from both groups received $10 \mathrm{mg}$ of rosuvastatin during a 20-week period. Additionally, patients from the first group attended a programme of physical training between the $10^{\text {th }}$ and $20^{\text {th }}$ week. A temporary increase of CK activity $48 \mathrm{~h}$ after the first round of exercise was noted in the exercise group, but these values returned to previous levels $48 \mathrm{~h}$ after the fifth round of exercise. Side effects such as muscular pain and stiffness were observed very early on, but their occurrence was not associated with the increase of CK. These results differ significantly from the results obtained by Thompson et al. [25], probably due to the smaller load with physical effort in the new study.

In another study, professional sportsmen with familial hypercholesterolaemia, taking all sorts of statins (excluding cerivastatin), were analysed; $78 \%$ of them did not tolerate the suggested statin therapy because of muscular pain. However, an increase of CK activity higher than the acceptable levels for sportsmen was not observed [27].

There is no unambiguous answer in the literature as to whether the treatment of physical exercise in the scheme of early cardiac rehabilitation is safe in patients undergoing therapy with statins. Does clinical practice offer any hints?

Although there are almost no data from large clinical trials about the possible effect of statin therapy on the whole process of cardiac rehabilitation, some clinical conclusions can be drawn from case reports. In 2009 we published an article reporting a case of severe myopathy during therapy with simvastatin in a patient undergoing early cardiac rehabilitation after $\mathrm{PCI}$ [28]. In the presented case, a high dose of simvastatin, together with too intensive physical training in the poorly trained patient, led to the development of life-threatening rhabdomyolysis. Our patient also presented with abnormal structure of the left kidney in ultrasonography (post-inflammatory changes? renal cirrhosis?) and abnormal kidney function. These abnormalities might have had a significant influence on statin metabolism and unfortunately had not been taken into consideration before the patient was qualified for the rehabilitation programme [28].

\section{Conclusions}

The careful selection of patients for both treatment with statins and the gradual intensification of physical training in the course of cardiac rehabilitation appears to be fundamentally important. The general condition and the previous physical activity of the patient should be assessed, together with all the factors presented above that 
can influence the safety of statin therapy. Such a procedure will help clinicians to achieve the maximal benefit of cardiac rehabilitation with minimal risk of serious side effects of simultaneously conducted hyperlipidaemia treatment. In our opinion, the benefits of the secondary prevention of CHD achieved with statins seem to outweigh the hazards of this kind of therapy. However, the question as to whether patients taking statins are the best candidates for early cardiac rehabilitation still remains unanswered.

\section{References}

1. Rudnicki S. Rehabilitacja w chorobach układu krążenia i po operacjach serca. In: Kwolek A. Rehabilitacja medyczna [Polish]. Wydawnictwo Medyczne Urban\&Partner, Wroctaw 2003; 309-38.

2. Narodowy Program Profilaktyki i Leczenia Chorób Układu Sercowo-Naczyniowego POLKARD. Raport o stanie rehabilitacji kardiologicznej w Polsce. Gdańsk, Łodź, Poznań. Tarnowskie Góry. Ustroń. Warszawa, sierpień 2004 [Polish]. Available at: www.polkard.org.

3. de Lemos JA, Blazing MA, Wiviott SD, et al. Early intensive vs delayed conservative simvastatin strategy in patients with acute coronary syndromes: phase $Z$ of $A$ to $Z$ trial. JAMA 2004; 292: 1307-16.

4. Barylski M, Mikhailidis DP, Rysz J, Banach M. Risk factor modification after ACS. Non-pharmacological management after acute coronary syndromes. Arch Med Sci 2010; 6: S64-75.

5. Tałałaj-Pastuszak B, Wysokiński A. Wczesna rehabilitacja kardiologiczna w „Szpitalu Uzdrowiskowym” w Nałęczowie [Polish]. Ann Univ M Curie Skłodowska, Sectio D, 2005, 60, 16, 560: 485-488.

6. Packard CJ. Risk factor modification after ACS. Benefits of lipid regulation in acute coronary syndrome. Arch Med Sci 2010; 6: S76-82.

7. Wainwright G, Mascitelli L, Goldstein MR. Cholesterollowering therapy and cell membranes. Stable plaque at the expense of unstable membranes? Arch Med Sci 2009; 5: 289-95.

8. Angelopoulos J, Krassakopoulos N, Natanson R, Boukas S, Sampalis JS. Co-administration of ezetimibe and a statin in management of dyslipidemias: a meta-analysis of clinical trials. Arch Med Sci 2009; 5: 347-63.

9. Thompson PD, Clarkson P, Karas RH. Statin-associated myopathy. JAMA 2003; 289: 1681-90.

10. Bruckert E, Hayem G, Dejager S, et al. Mild to moderate muscular symptoms with high-dosage statin therapy in hyperlipidemic patients - the PRIMO Study. Cardiovasc Drugs Ther 2005; 19: 403-14.

11. Graham DJ, Staffa JA, Shatin D, et al. Incidence of hospitalized rhabdomyolysis in patients treated with lipidlowering drugs. JAMA 2004; 292: 2585-90.

12. Harper CR, Jacobson TA. The broad spectrum of statin myopathy: from myalgia to rhabdomyolysis. Curr Opin Lipidol 2007; 18: 401-8.

13. Lane R, Phillips M. Rhabdomyolysis. BMJ 2003; 327: $115-6$.

14. Ucar M, Mjörndal T, Dahlqvist R. HMG-CoA reductase inhibitors and myotoxicity. Drug Saf 2000; 22: 441-57.

15. Hansen KE, Hildebrand JP, Ferguson EE, et al. Outcomes in 45 patients with statin-associated myopathy. Arch Intern Med 2005; 165: 2671-6.
16. Antons KA, Williams CD, Baker SK, et al. Clinical perspectives of statin-induced rhabdomyolysis. Am J Med 2006; 119: 400-9.

17. Wortmann RL. Dose-related stain myopathy. Is it an issue? Clev Clinic J Med 2005; 72: 751-6.

18. Kędzia A, Krysiak R, Madej A, et al. Is every case of muscale damage during hypolipemic therapy the side effect of this therapy? A case report. Pol Arch Med Wewn 2007; 117: 473-6.

19. Lilja JJ, Neuvonen M, Neuvonen PJ. Effects of regular consumption of grapefruit juice on the pharmacokinetics of simvastatin. Br J Clin Pharmacol 2004; 58: 56-60.

20. Bizzaro N, Bagolin E, Milani L, Ceresem C, Finco B. Massive rhabdomyolysis and simvastatin. Clin Chem 1992; 38: 1504.

21. Unnikrishnan D. Exertion-induced rhabdomyolysis in a patent on statin therapy. Nephrol Dial Transplant 2005; 20: 244.

22. Hong YH, Won HS, Kim DI, et al. Rhabdomyolysis associated with statin medication, exercise and sauna. Korean Circ J 2008; 38: 284-6.

23. Vladutiu GD, Genetic predisposition to statin myopathy. Curr Opin Rheumatol 2008; 20: 648-55.

24. Małecki R. Rabdomioliza - postępowanie w warunkach opieki podstawowej [Polish]. Kardiologia na co Dzień 2007; 2: 64-68.

25. Thompson PD, Zmuda JM, Domalik LJ, Zimet RJ, Staggers J, Guyton JR. Lovastatin increases exercise-induced skeletal muscle injury. Metabolizm 1997; 46: 1206-10.

26. Coen PM, Flynn MG, Markofski MM, Brandt DP, Hannemann RE. Adding exercise training to rosuvastatin treatment: influence on serum lipids and biomarkers of muscle and liver damage. Metab Clin Exper 2009; 58 : 1030-8.

27. Sinzinger $\mathrm{H}, \mathrm{O}$ 'Grady JO. Professional athletes suffering from familial hypercholesterolaemia rarely tolerate statin treatment because of muscular problems. Br J Clin Pharmacol 2005; 57: 525-8.

28. Dybała A, Grzywa-Celińska A, Mosiewicz J, Myśliński W. Myopathy in the curse of hypolipemic therapy in patient undergoing early cardiac rehabilitation after the percutation after the percutaneous coronary intervention - a case report. Pol Merk Lek 2009; 27: 226-8. 